\title{
THIS ISSUE OF THE JOURNAL OF URBAN HEALTH
}

Emerging infectious diseases comprise a salient topic in modern health care, one that concerns many physicians and researchers deeply. New disease processes, and the re-emergence of old diseases that were thought to be things of the past, should serve to remind us that health care-notably in the realm of public health-is, first, an exercise in vigilance. In June 1995, the New York Academy of Medicine hosted a multidisciplinary conference, "Emerging Infectious Diseases: Meeting the Challenge," as one acknowledgement of the need for such vigilance. The conference brought together specialists in the basic sciences and public health, each of whom presented her or his perspective on the problem and, in so doing, helped to illustrate the magnitude of it. The conference also included an address by Ms. Laurie Garrett, a science and medical writer, whose report lent a nonmedical, nonspecialist viewpoint to the topic and helped to dramatize the enormity of the problem in human terms. In this issue, we offer a sampling of the papers presented at the conference: some addresses are reproduced in full; others appear as part of the summaries of the two-day meeting.

Two original articles are also included in this issue of the Journal of Urban Health. In one of them, Pick reports that the informal economy is a major source of income, especially for women in most urban centers of the world. His interesting report on street vendors and their children in Johannesburg, South Africa, is one of the first efforts to define the living arrangements, illnesses, and healthutilization behavior of this vulnerable group. It is clear that in South Africa, and probably in almost all urban areas, special efforts must be made to bring such people, especially women in the informal economy, to adequate health care services. Although the actual frequency of illnesses, both acute and chronic, was not much higher than reported in other populations (indeed, the prevalence of chronic illnesses seems low), it probably reflects the good health that is necessary for such women to continue to pursue their work in the informal economy.

In the other original article offered in this issue, Polednak examines mortality 
rates in Hartford, Connecticut, and compares them with similar rates for the South Bronx area of New York City. The South Bronx and other large inner-city regions in large metropolitan centers are notorious for having exceptionally high death rates; studies such as Polednak's help us to discern both the similarities and differences that obtain in the mortality statistics in at least one smaller city in the US; most probably, similar phenomena will be found in many others. As this paper makes clear, poverty affects health in cities everywhere, but some causes of death, such as cancer and stroke, are, perhaps surprisingly, more prevalent in the smaller community. This work deserves careful reading, and careful consideration thereafter.

Drug addiction, especially in those with HIV, is one of the great morbidities of our present urban milieu. The US, however, seems possessed of a certain schizophrenia about treating addiction: a curious mixture of caring and punitiveness obtains among the public at large and even among physicians. Drawing on a large and accumulating body of experience, Stein and Fleischman present the view of the New York Academy of Medicine on the subject of substance use. The Academy's report emphasizes that addiction is a medical problem, and that a medical approach should be taken toward substance use and abuse. The report documents the Academy's position thoroughly and concludes with a series of recommendations that can be a useful guide for all of us. It is clear, however, that the public in general, including the physicians among us, needs to be educated about the essentially medical nature of the problem before any real changes in the care of addicted individuals can take place.

This issue's Classic Paper section reproduces an article published originally in the December 1953 issue of the Bulletin of the New York Academy of Medicine. The offering, "Active Immunization Against Poliomyelitis," was presented by Dr. Herald R. Cox to the "Symposium on Poliomyelitis: Its Control and Prevention," which was held at the Academy on April 2, 1953. A perspective on the importance-indeed, the prognostication-of Dr. Cox's paper is presented in Dr. Katz's commentary.

Our Urban Health Data section returns with a graphic examination of the incidence of cryptosporidiosis among HIV-infected and immunocompetent persons in New York City. The decline in incidence among the former population is noted to parallel an increase in the use of improved antiretroviral agents.

This issue concludes with a change of pace. We offer reviews of three disparate books, on marriage, inherited metabolic diseases, and medical writing. 